\title{
Peramalan Nilai Tukar Petani Kabupaten Lamongan dengan Arima
}

\author{
Mohammad Syaiful Pradana \\ Jl. Airlangga 03 Sukodadi Lamongan \\ e-mail:syaifulp@unisda.ac.id \\ Dinita Rahmalia \\ Jl. Airlangga 03 Sukodadi Lamongan \\ e-mail: dinitarahmalia@unisda.ac.id \\ Ericha Dwi Ayu Prahastini \\ Jl. Airlangga 03 Sukodadi Lamongan \\ e-mail: ericha27d@gmail.com
}

\begin{abstract}
Agriculture is a sector that has a significant role for the Indonesian economy. In Lamongan Regency, about 35.71 percent of the workers depends on the primary agricultural sector, so it is not surprising that the agricultural sector is the basis of growth, especially in rural areas. Agricultural development is oriented towards improving the welfare of farmers. One of the measurements the level of farmer welfare is by calculating the Farmer Exchange Rate (NTP). The purpose of this research is to predict the NTP values in the following year and to find out which agricultural subsector needs to be controlled by the Lamongan district government. The sub-sectors in this research are food crops, horticulture, smallholder plantations, animal husbandry and fisheries. Forecasting the NTP value uses the ARIMA method with the help of the $R$ application. Based on the results of the analysis and discussion, food plants have a relatively low NTP value, namely an average of $\geq 100$ per month for a period of 3 years and have the highest NTP reduction in 2019 of $1025 \%$.
\end{abstract}

Keywords: Forecasting, Farmer Exchange Rate, Arima

Abstrak: Pertanian merupakan sektor yang memiliki peranan signifikan bagi perekonomian Indonesia. Pada kabupaten Lamongan sekitar 35,71 persen tenaga kerja bergantung pada sektor pertanian primer maka tidak heran sektor pertanian menjadi basis pertumbuhan terutama didaerah pedesaan. Pembangunan pertanian berorientasi pada perbaikan kesejahteraan petani. Salah satu alat ukur tingkat kesejahteraan petani dengan melakukan penghitungan Nilai Tukar Petani (NTP). Tujuan penelitian ini untuk meramalkan nilai NTP pada tahun selanjutnya dan mengetahui sub sector pertanian yang perlu dikendalikan oleh pemerintah kabupaten Lamongan. Sub sektor dalam penelitian ini yaitu tanaman pangan, hortikultura, perkebunan rakyat, peternakan dan perikanan. Peramalan nilai NTP menggunakan metode ARIMA dengan bantuan aplikasi R. Berdasarkan hasil analisis dan pembahasan, tanaman pangan memiliki nilai NTP yang tergolong rendah yakni rata-rata $\geq 100$ pada setiap bulannya selama jangka waktu 3 tahun dan memiliki penurunan NTP tertinggi pada tahun 2019 sebesar 10,25\%.

Kata Kunci: Peramalan, Nilai Tukar Petani, Arima 


\section{Pendahuluan}

Sebagai salah satu negara yang termasuk dalam wilayah tropis, Indonesia memiliki potensi pertanian yang sangat baik, terutama untuk pertanian tropis. Salah satu produk pertanian tropika Indonesia yang berpotensi menjadi andalan adalah produk pertanian segar dalam bentuk buah-buahan dan sayuran. Produk lain yang turut menjadi andalan adalah rempah-rempah dan bahan bakar nabati. Indonesia merupakan Negara agraris yang memiliki potensi besar dan sumber daya alam yang melimpah untuk produk pertanian. Di sektor pertanian Indonesia memiliki beragam jenis tenaman, hal ini didukung kondisi iklim tropis yang berbeda, dibidang tanaman pangan di Indonesia memiliki tanaman unggul seperti padi, kedelai, kacang tanah, ubi kayu dan berbagai jenis faritas yang lain (Prastowo, 2015).

Pertanian merupakan sektor yang memiliki peranan signifikan bagi perekonomian Indonesia. Pada tahun 2018 kontribusi pertanian pada laju Pertumbuhan Domestik Bruto (PDB) mencapai 1.005,40 trilliun dan produksi petani jagung nasional mampu mengekspor sebanyak 380 ribu ton (RI, 2018). Fakta tersebut menguatkan pertanian sebagai megasektor yang sangat vital bagi perekonomian Indonesia. Pertanian juga dipandang sebagai suatu sektor yang memiliki kemampuan khusus dalam memadukan pertumbuhan dan pemerataan (growth with equity) atau pertumbuhan yang berkualitas.

Terlebih sekitar 35,71 persen tenaga kerja di kabupaten Lamongan bergantung pada sektor pertanian primer maka tidak heran sektor pertanian menjadi basis pertumbuhan terutama di daerah pedesaan (Statistik, 2018a). Pertanian sudah lama disadari sebagai instrumen untuk mengurangi kemiskinan. Pertumbuhan sektor pertanian memiliki kemampuan khusus untuk mengurangi kemiskinan. Pertanian di kabupaten Lamongan dapat dilihat dari struktur perekonomian yang membentuk kabupaten Lamongan. Berdasarkan data produk domestik regional bruto kabupaten Lamongan tahun 2018, sektor pertanian menyumbang 35,18 persen dari total keseluruhan produk domestik bruto kabupaten Lamongan (Statistik, 2018b).

Kondisi di atas menunjukkan sektor pertanian sudah selayaknya dijadikan sebagai suatu sektor ekonomi yang sejajar dengan sektor lainnya. Sektor ini tidak lagi hanya berperan sebagai aktor pembantu apalagi figuran bagi pembangunan nasional, tetapi harus menjadi pemeran utama yang sejajar dengan sektor industri. Tidak dapat dipungkiri, keberhasilan sektor industri sangat tergantung dari pembangunan sektor pertanian yang dapat menjadi landasan pertumbuhan ekonomi (Arifin, 2004). Sebagai daerah yang mempunyai potensi besar pertanian, sudah selayaknya pembangunan sektor pertanian mendapat perhatian khusus dan hasilnya dapat dipandang sebagai salah satu kunci sukses pemerintah dalam mewujudkan kesejahteraan masyarakat (Rohmatullah, Rahmalia, \& Pradana, 2019). 
Pembangunan pertanian berorientasi pada perbaikan kesejahteraan petani. Salah satu alat ukur tingkat kesejahteraan petani dengan melakukan penghitungan Nilai Tukar Petani (NTP). NTP merupakan hubungan antara hasil yang dijual petani dengan barang dan jasa yang dibeli petani (Rachmat, 2013). Dengan kata lain, NTP merupakan alat ukur kemampuan tukar barang-barang (produk) pertanian yang dihasilkan petani dengan barang atau jasa yang diperlukan untuk konsumsi rumahtangga petani dan keperluan dalam memproduksi barang-barang pertanian. NTP disajikan dalam bentuk indeks dengan tahun tertentu sebagai tahun dasar.

Dari data NTP Tahun 2019 ini tercermin tingkat kesejahteraan petani kabupaten Lamongan secara makro. Keberadaan data ini sangatlah penting sebagai salah satu tolak ukur atas keberhasilan pembangunan yang dilakukan oleh pemerintah dan masyarakat. Agar hasil yang diperoleh akurat dan tepat waktu, diperlukan dukungan dari berbagai pihak, terutama Pemerintah dan masyarakat sebagai sumber data. Melihat betapa pentingnya NTP ini, peramalan nilai NTP pada tahun berikutnya akan sangat bermanfaat. Hasil dari nilai tersebut, dapat menjadi patokan untuk mengantisipasi segala situasi pada tahuntahun berikutnya serta bagaimana kiranya dapat mengendalikan nilai NTP agar terus naik sehingga meningkatkan kesejahteraan masyarakat Lamongan. Untuk dapat melihat nilai NTP di tahun selanjutnya, dapat dilakukan dengan menggunakan teori peramalan pada Aplikasi R yang akan mengolah data nilai NTP pada tahun sebelumnya untuk menghasilkan ramalan nilai NTP yang dibutuhkan. Oleh karena itu, tujuan penelitian ini yaitu untuk meramalkan nilai NTP pada tahun selanjutnya dan mengetahui sub sector pertanian yang perlu dikendalikan oleh pemerintah kabupaten Lamongan.

\section{Metode Penelitian}

\subsection{ARIMA (Autoregressive Integrated Moving Average)}

Model Autoregresif Integrated Moving Average (ARIMA) adalah model yang secara penuh mengabaikan independen variabel dalam membuat peramalan. ARIMA menggunakan nilai masa lalu dan sekarang dari variabel dependen untuk menghasilkan peramalan jangka pendek yang akurat. ARIMA cocok jika observasi dari deret waktu (time series) secara statistik berhubungan satu sama lain (dependent). Tujuan model ini adalah untuk menentukan hubungan statistik yang baik antar variabel yang diramal dengan nilai historis variabel tersebut sehingga peramalan dapat dilakukan dengan model tersebut (Hendranata, 2003).

Model ARIMA terdiri dari tiga langkah dasar, yaitu tahap identifikasi, tahap penaksiran dan pengujian dan pemeriksaan diagnistik. Selanjutnya model ARIMA dapat digunakan untuk melakukan peramalan jika model yang diperoleh memadai. 
a. Stasioneritas dan Nonstasioneritas

Hal yang perlu diperhatikan adalah bahwa kebanyakan deret berkala bersifat nonstasioner dan bahwa aspek-aspek AR dan MA dari model ARIMA hanya berkenaan dengan deret berkala yang stasioner. Stasioneritas berarti tidak terdapat pertumbuhan atau penurunan pada data. Data secara kasarnya harus horizontal sepanjang sumbu waktu. Dengan kata lain, fluktuasi data berada di sekitar suatu nilai rata-rata yang konstan, tidak tergantung pada waktu dan varians dari fluktuasi tersebut pada pokoknya tetap konstan setiap waktu.

Suatu deret waktu yang tidak stasioner harus diubah menjadi data stasioner dengan melakukan differencing. Yang dimaksud dengan differencing adalah menghitung perubahan atau selisih nilai observasi. Nilai selisih yang diperoleh dicek lagi apakah stasioner atau tidak. Jika belum stasioner maka dilakukan differencing lagi. Jika varians tidak stasioner, maka dilakukan transformasi logaritma.

b. Klasifikasi model ARIMA

Model Box-Jenkins (ARIMA) dibagi kedalam 3 kelompok, yaitu: model $a u$ toregressive (AR), moving average (MA), dan model campuran ARIMA (autoregresive moving average) yang mempunyai karakteristik dari dua model pertama.

1) Autoregressive Model (AR), Model yang menjelaskan pergerakan suatu variabel melalui variabel itu sendiri pada perode waktu sebelumnya. Bentuk umum model autoregressive dengan ordo $p(\mathrm{AR}(p))$ atau model ARIMA $(p, 0,0)$ dinyatakan sebagai berikut:

$$
Z_{t}=\mu^{\prime}+\varphi_{1} Z_{t-1}+\varphi_{2} Z_{t-2}+\ldots+\varphi_{p} Z_{t-p}+a_{t}
$$

$$
\text { dimana: } \begin{aligned}
\mu^{\prime} & =\text { suatu konstanta } \\
\varphi_{p} & =\text { parameter autoregresif ke- } p \\
a_{t} & =\text { nilai kesalahan pada saat } t
\end{aligned}
$$

2) Moving Average Model (MA), Rata-rata bergerak yang melihat pergerakan variabelnya melalui residual di masa lalu. Bentuk umum model moving average ordo $q(\mathrm{MA}(q))$ atau $\operatorname{ARIMA}(0,0, q)$ dinyatakan sebagai berikut:

$$
Z_{t}=\mu^{\prime}+a_{t}-\theta_{1} a_{t-1}-\theta_{2} a_{t-2}-\ldots-\theta_{q} a_{t-k}
$$

dimana: $\quad \mu^{\prime}=$ suatu konstanta

$$
\begin{aligned}
\theta_{1}-\theta_{q} & =\text { parameter-parameter moving average } \\
a_{t-k} & =\text { nilai kesalahan pada saat } t-k
\end{aligned}
$$

3) Model Campuran

a. Proses ARMA 
Model umum untuk campuran proses AR(1) murni dan MA(1) murni, misal ARIMA $(1,0,1)$ dinyatakan sebagai berikut:

$$
\begin{aligned}
& Z_{t}=\mu^{\prime}+\varphi_{1} Z_{t-1}+\varphi_{2} Z_{t-2}+\ldots+\varphi_{p} Z_{t-p}-\theta_{1} a_{t-1}-\theta_{2} a_{t-2}-\ldots-\theta_{q} a_{t-q} \\
& \text { atau } \\
& \left(1-\varphi_{1} B-\varphi_{2} B^{2}-\ldots-\varphi_{p} B^{p}\right) Z t=\mu^{\prime}+\left(1-\theta_{1} B-\theta_{2} B^{2}-\ldots-\theta_{q} B^{q}\right) a_{t}
\end{aligned}
$$

$\operatorname{AR}(1)$

MA(1)

\section{b. Proses ARIMA}

Apabila nonstasioneritas ditambahkan pada campuran proses ARMA, maka model umum ARIMA $(p, d, q)$ terpenuhi. Persamaan untuk kasus sederhana ARIMA $(1,1,1)$ adalah sebagai berikut:

$$
\begin{aligned}
\varphi_{p}(B)(1-B)^{d} Z_{t}=\theta_{q}(B) a_{t} \\
\text { dimana: } \mathrm{p}=\text { Orde AR } \\
\mathrm{d}=\text { Orde Differencing Non Musiman } \\
\mathrm{q}=\text { Orde MA }
\end{aligned}
$$

\section{c. Musiman dan Model ARIMA}

Musiman didefinisikan sebagai suatu pola yang berulang-ulang dalam selang waktu yang tetap. Untuk data yang stasioner, faktor musiman dapat ditentukan dengan mengidentifikasi koefisien autokorelasi pada dua atau tiga time-lag yang berbeda nyata dari nol. Autokorelasi yang secara signifikan berbeda dari nol menyatakan adanya suatu pola dalam data. Untuk mengenali adanya faktor musiman, seseorang harus melihat pada autokorelasi yang tinggi.

Untuk menangani musiman, notasi umum yang singkat adalah:

$$
\begin{gathered}
\text { ARIMA }(p, d, q)(P, D, Q) \mathrm{S} \\
\text { dimana }(p, d, q)=\text { bagian yang tidak musiman dari model } \\
(P, D, Q)=\text { bagian musiman dari model } \\
\mathrm{S}=\text { jumlah periode per musim }
\end{gathered}
$$

\section{d. Identifikasi}

Proses identifikasi dari model musiman tergantung pada alat-alat statistik berupa autokorelasi dan parsial autokorelasi, serta pengetahuan terhadap sistem (atau proses) yang dipelajari.

e. Penaksiran Parameter

Ada dua cara yang mendasar untuk mendapatkan parameter-parameter tersebut: 
1) Dengan cara mencoba-coba (trial and error), menguji beberapa nilai yang berbeda dan memilih satu nilai tersebut (atau sekumpulan nilai, apabila terdapat lebih dari satu parameter yang akan ditaksir) yang meminimumkan jumlah kuadrat nilai sisa (sum of squared residual).

2) Perbaikan secara iteratif, memilih taksiran awal dan kemudian membiarkan program komputer memperhalus penaksiran tersebut secara iteratif.

\section{f. Pengujian Parameter Model}

1) Pengujian masing-masing parameter model secara parsial $(t$-test $)$

2) Pengujian model secara keseluruhan (Overall F test)

Model dikatakan baik jika nilai error bersifat random, artinya sudah tidak mempunyai pola tertentu lagi. Dengan kata lain model yang diperoleh dapat menangkap dengan baik pola data yang ada. Untuk melihat kerandoman nilai error dilakukan pengujian terhadap nilai koefisien autokorelasi dari error, dengan menggunakan salah satu dari dua statistik berikut:

1) Uji Q Box dan Pierce:

$$
Q=n^{\prime} \sum_{k=1}^{m} r_{k}^{2}
$$

2) Uji Ljung-Box:

$$
Q=n^{\prime}\left(n^{\prime}+2\right) \sum_{k-1}^{m} \frac{r_{k}^{2}}{\left(n^{\prime}-k\right)}
$$

Menyebar secara Chi Kuadrat $\left(\chi^{2}\right)$ dengan derajat bebas

$$
\begin{aligned}
&(\mathrm{db})=(\mathrm{k}-\mathrm{p}-\mathrm{q}-\mathrm{P}-\mathrm{Q}) \\
& \text { dimana: }\mathrm{n}\urcorner=\mathrm{n}-(\mathrm{d}+\mathrm{SD}) \\
& \mathrm{d}=\text { ordo pembedaan bukan faktor musiman } \\
& \mathrm{D}=\text { ordo pembedaan faktor musiman } \\
& \mathrm{S}=\text { jumlah periode per musim } \\
& \mathrm{m}=\text { lag waktu maksimum } \\
& r_{k}=\text { autokorelasi untuk time lag } 1,2,3,4, \ldots, k
\end{aligned}
$$

Kriteria pengujian:

Jika $\mathrm{Q} \leq \chi^{2}(\alpha, d b)$, berarti: nilai error bersifat random (model dapat diterima).

Jika $\mathrm{Q}>\chi^{2}(\alpha, d b)$, berarti: nilai error tidak bersifat random (model tidak dapat diterima). 
g. Pemilihan Model Terbaik

Untuk menentukan model yang terbaik dapat digunakan standard error estimate berikut:

$$
S=\left[\frac{S S E}{n-n_{p}}\right]^{1 / 2}=\left[\frac{\sum_{t=1}^{n}\left(Y_{t}-\hat{Y}_{t}\right)^{2}}{n-n_{p}}\right]^{1 / 2}
$$

dimana: $Y_{t}=$ nilai sebenarnya pada waktu ke-t

$\hat{Y_{t}}=$ nilai dugaan pada waktu ke-t

$t$ Model terbaik adalah model yang memiliki nilai standard error estimate (S) yang paling kecil. Selain nilai standard error estimate, nilai rata-rata persentase kesalahan peramalan (MAPE) dapat juga digunakan sebagai bahan pertimbangan dalam menentukan model yang terbaik yaitu:

$$
\text { MAPE }=\frac{\sum_{t=1}^{T} \frac{\left|Y_{t}-\hat{Y}_{t}\right|}{Y_{t}}}{T} \times 100 \%
$$

dimana: $T=$ banyaknya periode peramalan/dugaan.

h. Peramalan Dengan Model ARIMA

Notasi yang digunakan dalam ARIMA adalah notasi yang mudah dan umum. Tetapi untuk menggunakannya dalam peramalan mengharuskan dilakukan suatu penjabaran dari persamaan tersebut dan menjadikannya sebuah persamaan regresi yang lebih umum.

\section{Hasil dan Pembahasan}

\subsection{NTP Setiap Sub Sektor 2017-2019}

Berdasarkan Gambar 1 menunjukkan Nilai Tukar Petani tiap sub sektor tahun 2017. Kenaikan tertinggi pada sektor perkebunan rakyat di bulan Agustus yakni meningkat 11,64 persen dari bulan sebelumnya. Sedangkan penurunan tertinggi pada sektor peternakan di bulan Februari yakni menurun 10,32 persen dari bulan sebelumnya. Sedangkan Gambar 2 menunjukkan menunjukkan Nilai Tukar Petani tiap sub sektor tahun 2018. Kenaikan tertinggi pada tahun 2018 terletak pada sektor holtikultura di bulan Juli yakni meningkat 18,62 persen dari bulan sebelumnya. Penurunan tertinggi pada sektor holtikultura di bulan Agustus yakni menurun 23,04 persen dari bulan sebelumnya. 
Untuk Subsektor pertanian di kabupaten Lamongan tahun 2019 yang dijelaskan oleh Gambar 3. Kenaikan tertinggi juga pada sektor holtikultura di bulan Juli yakni meningkat 42,04 persen dari bulan sebelumnya. Penurunan tertinggi pada sektor holtikultura di bulan September yakni menurun 31,89 persen dari bulan sebelumnya.

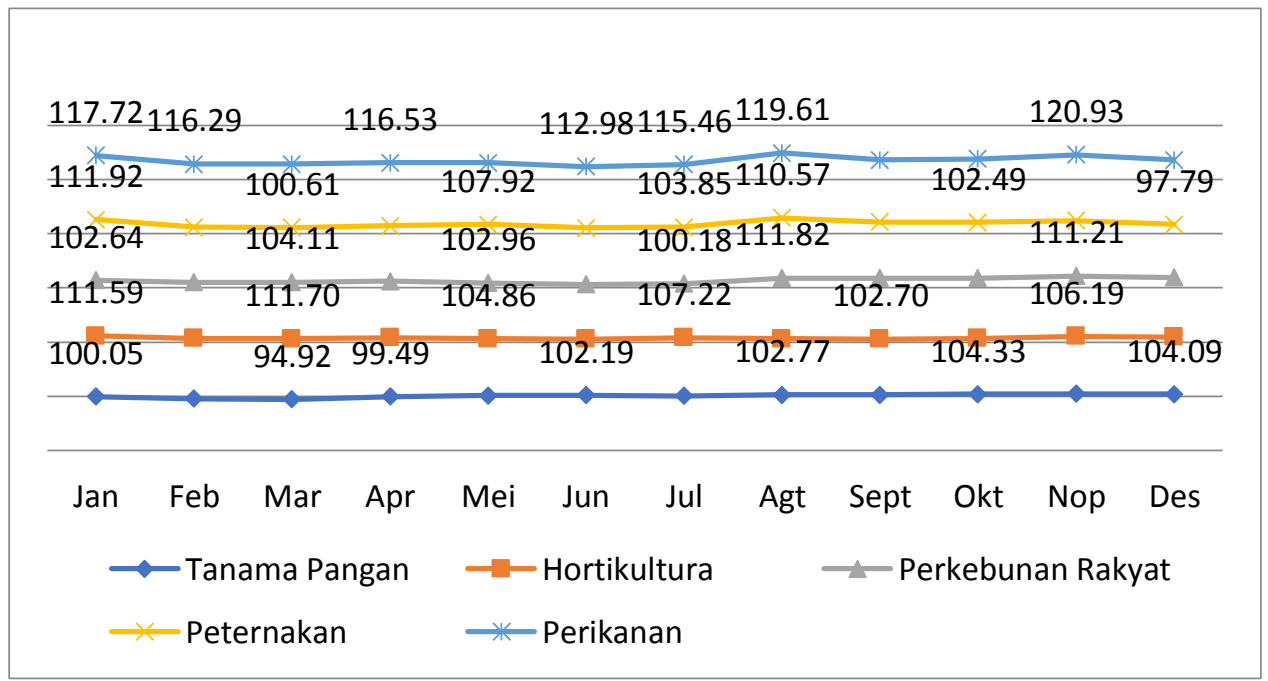

Gambar 1. Nilai Tukar Petani Tiap Sub Sektor Tahun 2017

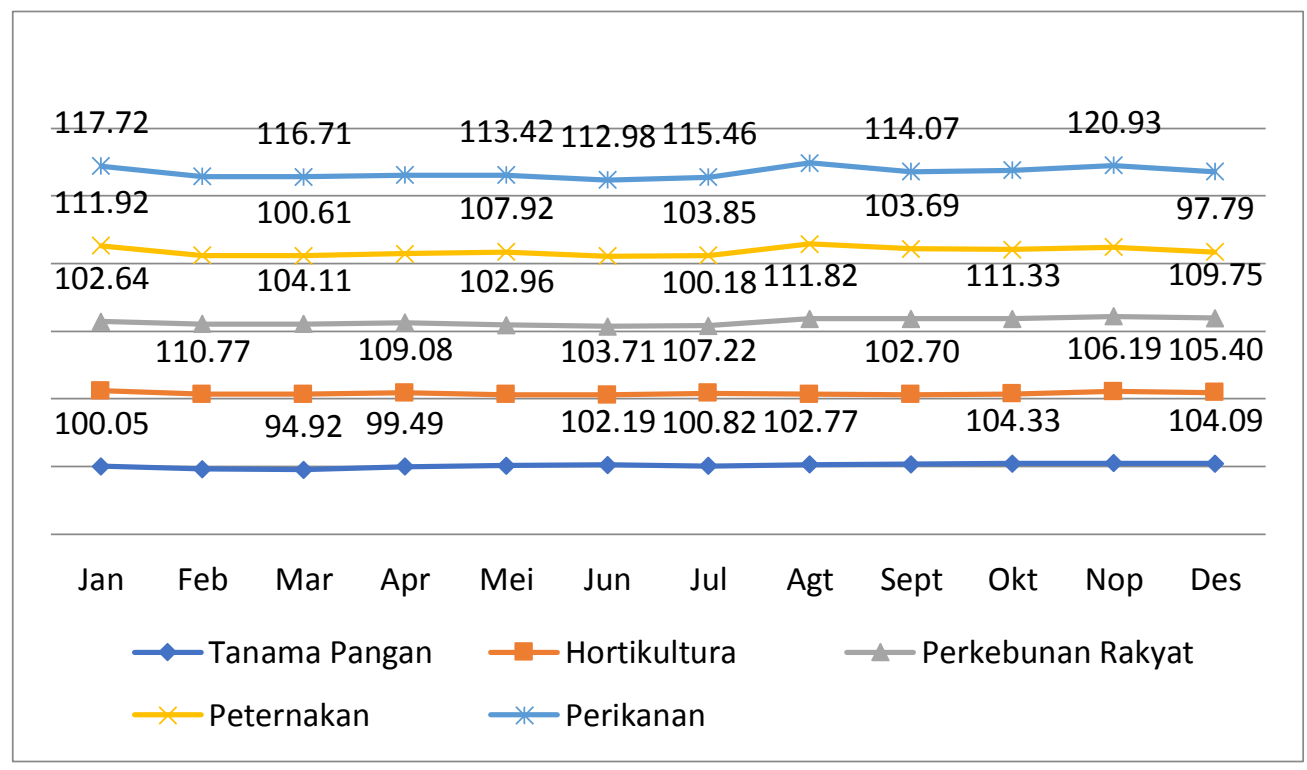

Gambar 2. Nilai Tukar Petani Tiap Sub Sektor Tahun 2018 


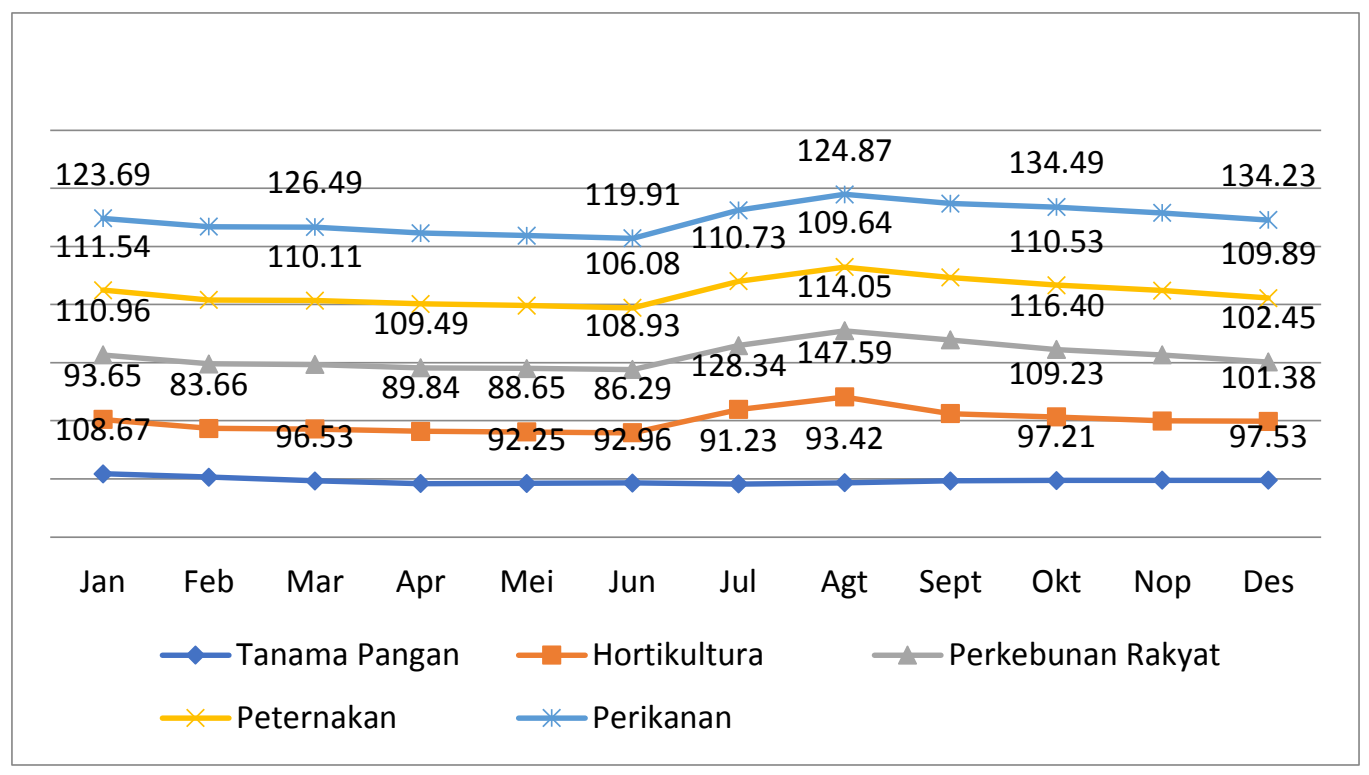

Gambar 3. Nilai Tukar Petani Tiap Sub Sektor Tahun 2019

\subsection{Peramalan NTP}

Pada Tabel 1 merupakan output dari data yang dimasukkan pada aplikasi $\mathrm{R}$ yang telah mengklasifikasikan secara otomatis nilai tukar petani kedalam tiap-tiap bulannya pada tahun 2017-2019.

Tabel 1. Pengklasifikasian NTP Tiap Bulan

\begin{tabular}{|c|c|c|c|c|c|c|c|c|c|c|c|}
\hline Jan & Feb & Mar & Apr & May & Jun & Jul & Aug & Sept & Oct & Nov & Dec \\
\hline 105.52 & 101.93 & 101.38 & 103.63 & 104.33 & 103.93 & 103.93 & 106.63 & 105.26 & 106.04 & 107.19 & 105.91 \\
\hline 107.48 & 105.76 & 102.78 & 100.03 & 100.44 & 100.62 & 105.29 & 105.53 & 106.08 & 106.80 & 107.27 & 108.37 \\
\hline 109.12 & 104.89 & 102.09 & 98.91 & 98.52 & 98.26 & 103.96 & 108.32 & 106.67 & 106.70 & 105.73 & 104.78 \\
\hline
\end{tabular}

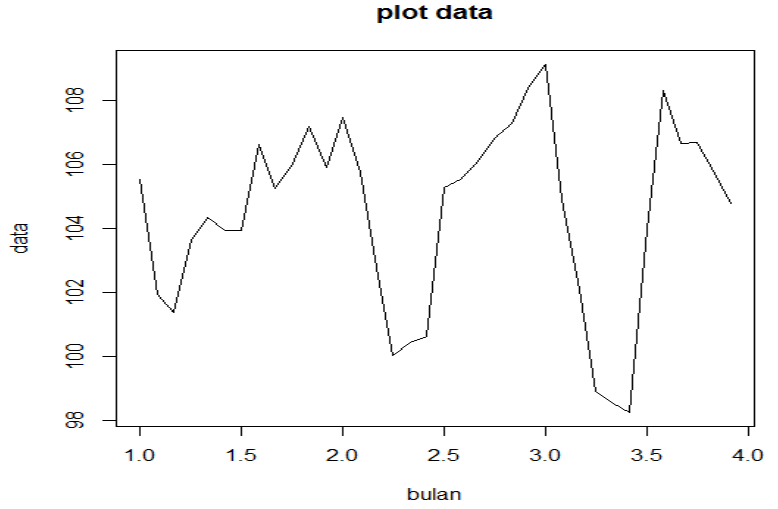

Gambar 4. Plot Data NTP Tiap Bulan 
Pada Gambar 4 menunjukkan plot data NTP yang telah dimasukkan setiap bulan. Data yang dimaksud pada grafik tersebut ialah Nilai Tukar Petani Kabupaten Lamongan pada kurun waktu 3 Tahun. Sedangkan pada keterangan Bulan ialah jangka waktu pada 3 tahun tersebut. 1,0 - 2,0 menunjukkan tahun pertama (2017), 2,0 - 3,0 menunjukkan tahun kedua (2018), 3,0 - 4,0 yang menunjukkan tahun terakhir yakni 2019. Pada grafik tersebut kita juga dapat menentukan apakah data tersebut telah stasioner atau belum.

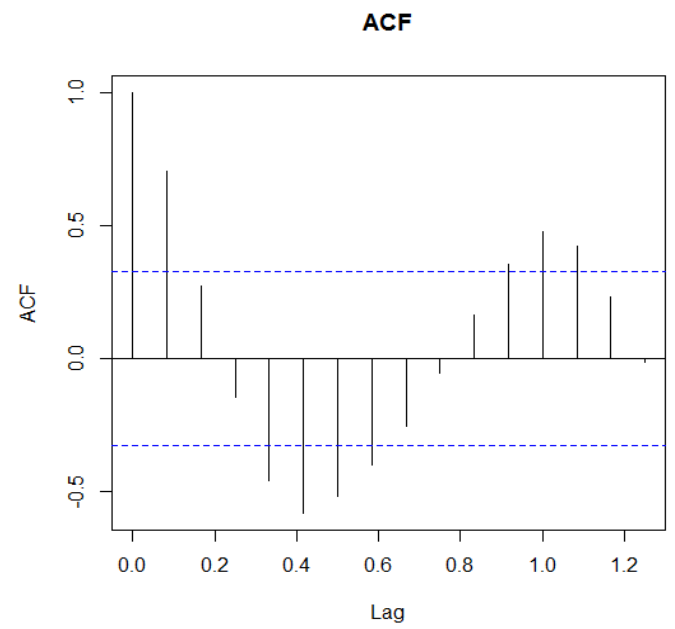

Gambar 5. Hasil ACF

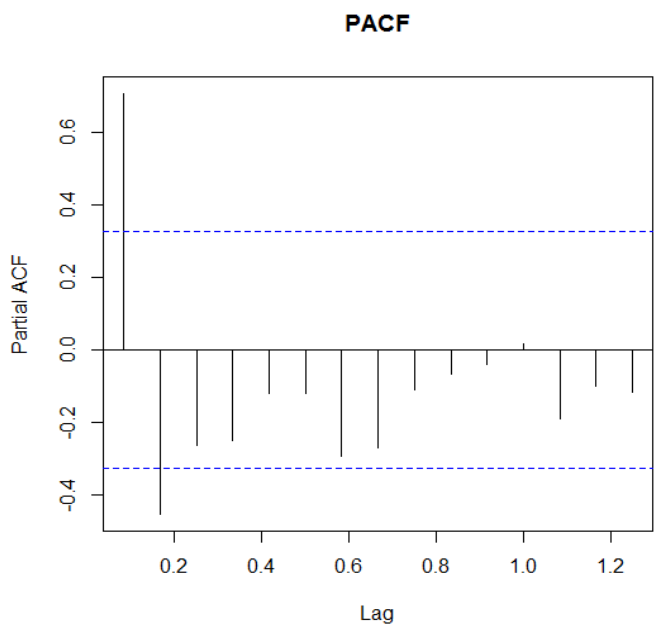

Gambar 6. Hasil PACF

Pada Gambar 5 menunjukkan hasil ACF (Auto Correlation Funcion) yang mengukur korelasi antar pengamatan dengan jeda $\mathrm{k}$, atau hubungan antara nilai-nilai yang beruntun dari variansi yang sama. Digunakan untuk menentukan kestasioneran data runtun waktu dan mengidentifikasi model analisisnya. Gambar 6 hasil PACF (Partial Auto Correlation Funcion) mengukur korelasi antar pengamatan dengan jeda kdan dengan mengontrol korelasi antar dua pengamatan dengan jeda kurang dari k. Pada Gambar 5 menunjukkan ACF yang keluar garis batas yaitu 2 lag, dan pada Gambar 6 menunjukkan PACF yang keluar garis batas yaitu 2 lag.

Tabel 2. Hasil Differencing

\begin{tabular}{|c|c|c|c|c|c|c|c|c|c|c|c|}
\hline Jan & Feb & Mar & Apr & May & Jun & Jul & Aug & Sept & Oct & Nov & Dec \\
\hline & -3.59 & -0.55 & 2.25 & 0.70 & -0.40 & 0.00 & 2.70 & -1.37 & 0.78 & 1.15 & -1.28 \\
\hline 1.57 & -1.72 & -2.98 & -2.75 & 0.41 & 0.18 & 4.67 & 0.24 & 0.55 & 0.72 & 0.47 & 1.10 \\
\hline 0.75 & -4.23 & -2.80 & -3.18 & -0.39 & -0.26 & 5.70 & 4.36 & -1.65 & 0.03 & -0.97 & -0.95 \\
\hline
\end{tabular}


Tabel 2. merupakan output dari data pada Tabel 1 yang telah differencing pada aplikasi R. Dilakukannya Differencing karena data yang dimasukkan pada Tabel 1 belum stasioner.

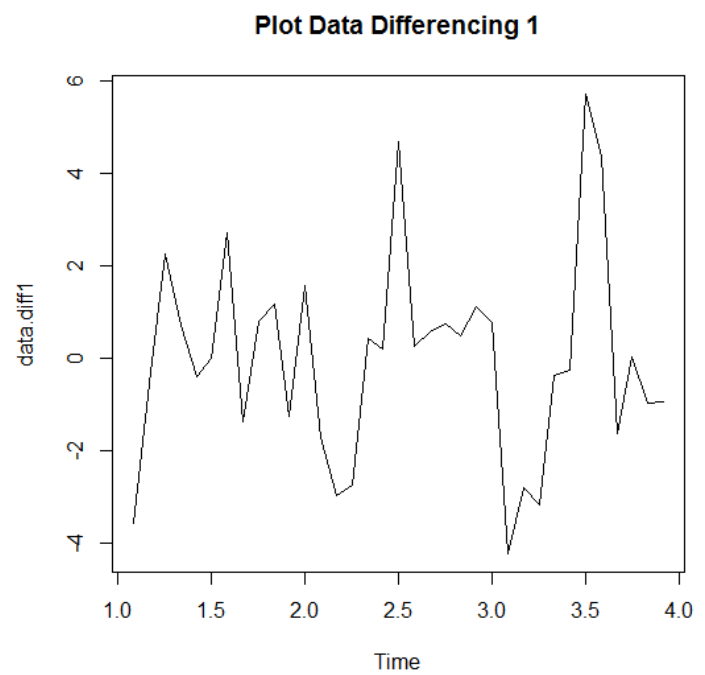

Gambar 7. Hasil Plot Data NTP Tiap Bulan yang Telah Differencing

Data pada Gambar 7 menunjukkan plot data pada NTP yang telah differencing. Data.diff1 yang dimaksud pada grafik tersebut ialah Nilai Tukar Petani Kabupaten Lamongan pada kurun waktu 3 Tahun yang telah melalui tahapan differencing sebanyak sekali. Sedangkan pada keterangan Time ialah jangka waktu pada 3 tahun tersebut. 1,0 - 2,0 menunjukkan tahun pertama (2017), 2,0 - 3,0 menunjukkan tahun kedua (2018), 3,0 - 4,0 yang menunjukkan tahun terakhir yakni 2019.

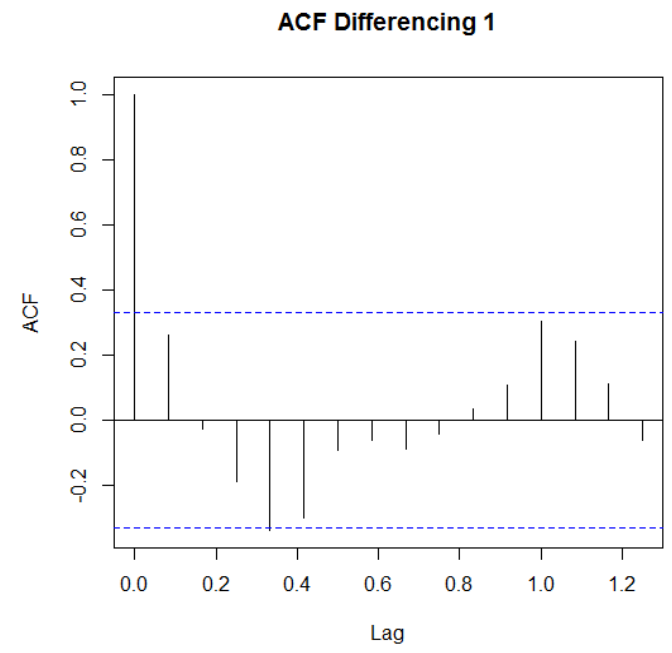

Gambar 8. Hasil ACF Differencing

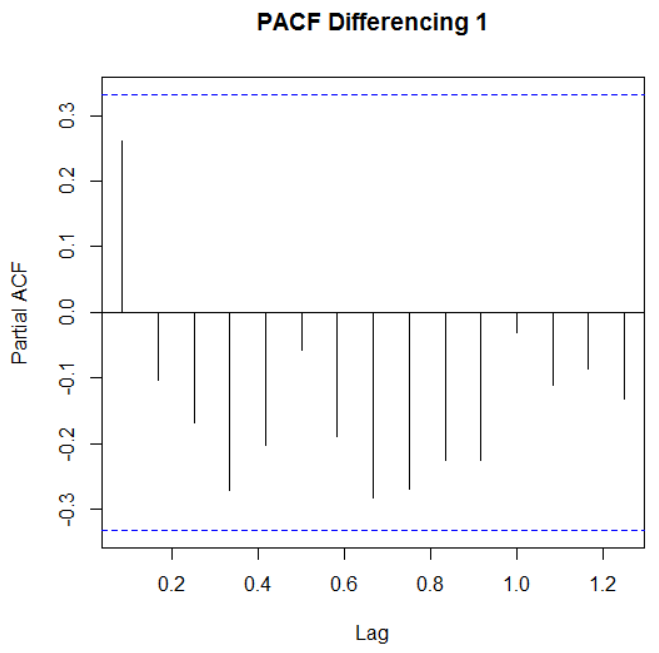

Gambar 9. Hasil PACF Differencing 
Pada Gambar 8 menunjukkan hasil ACF (Auto Correlation Funcion) yang mengukur korelasi antar pengamatan dengan jeda $\mathrm{k}$ atau hubungan antara nilai-nilai yang beruntun dari variansi yang sama. Digunakan untuk menentukan kestasioneran data runtun waktu dan mengidentifikasi model analisisnya. Gambar 9 hasil PACF (Partial Auto Correlation Funcion) mengukur korelasi antar pengamatan dengan jeda $\mathrm{k}$ dan dengan mengontrol korelasi antar dua pengamatan dengan jeda kurang dari k. Pada Gambar 8 menunjukkan ACF yang keluar garis batas yaitu 1 lag, dan pada Gambar 9 menunjukkan PACF yang keluar garis batas yaitu 0 lag.
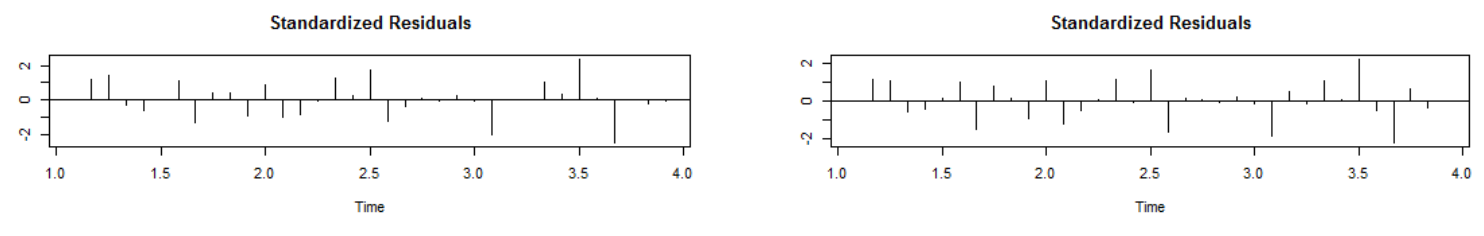

ACF of Residuals
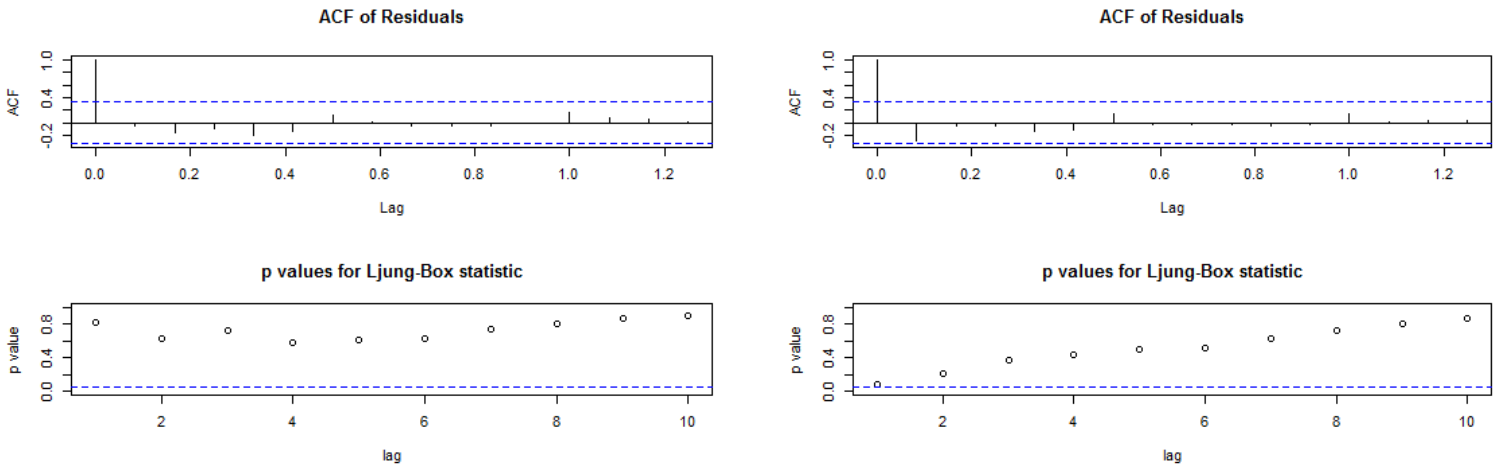

Gambar 10. Hasil Diagnosis dari ARIMA 1

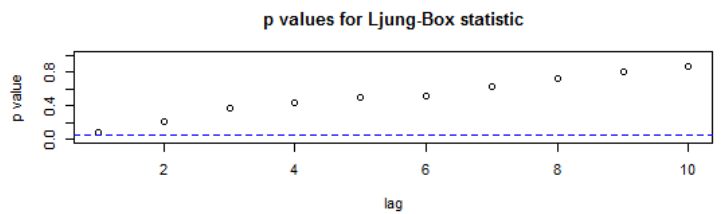

Gambar 11. Hasil Diagnosis dari ARIMA 2

Pada pemilihan ARIMA terbaik maka ada Uji yang dinamakan Uji Diagnostik yang meliputi: ACF of Residuals, dikatakan memenuhi white noise jika tidak ada lag (kesalahan) ( $\geq 1)$ yang keluar dari garis batas intervar. Sedangkan pada bagian $p$ value for LJung-Box Statistic garis 5\% menandakan residual tidak mengandung korelasi serial.

Gambar 10 menunjukkan hasil diagnosis dari ARIMA $1(1,1,0)$ dengan ACF 1, Differencing 1, dan PACF 0 dimana pada bagian ACF of Residuals dan $p$-value for LJung-Box Statistic telah memenuhi Uji diagnostik. Sedangkan pada gambar 11 menunujukkan hasil diagnosis dari ARIMA $2(0,1,0)$ dengan ACF 0, Differencing 1, dan PACF 0 dimana pada p-value for LJung-Box Statistic tidak memenuhi Uji diagnostik.

Dari penjelasan tersebut dapat diketahui bahwa NTP subsektor tahun 2017 kenaikan tertinggi pada sub sektor perkebunan rakyat di bulan Agustus yakni meningkat 11,64 dari bulan sebelumnya, tahun 2018 kenaikan tertinggi pada sektor 
holtikultura di bulan Juli yakni meningkat 18,62 dari bulan sebelumnya, sedangkan tahun 2019 kenaikan tertinggi juga pada sektor holtikultura di bulan Juli yakni meningkat 42,05 dari bulan sebelumnya.

Sedangkan jika melihat setiap sub sektor pada setiap tahunnya, selama tahun 2017-2019, pada tahun 2017 sub sektor yang mengalami penurunan NTP yaitu sub sektor peternakan sebesar 12,63 persen dan holtikultura sebesar 5,55 persen. Kenaikan NTP tertinggi selama tahun 2017 adalah sub sektor perkebunan rakyat sebesar 6,93 persen, diikuti sub sektor tanaman pangan sebesar 4,04 persen, dan sub perikanan sebesar 0,96 persen. Pada tahun 2018 sub sektor yang mengalami penurunan NTP yaitu sub sektor holtikultura sebesar 17,40 persen. Kenaikan NTP tertinggi selama tahun 2018 adalah sub sektor peternakan sebesar 14,34 persen, sub sektor perkebunan rakyat sebesar 2,45 persen, diikuti sub sektor perikanan sebesar 2,34 persen dan sektor tanaman pangan sebesar 2,26 persen. Pada tahun 2019 sub sektor yang mengalami penurunan NTP yaitu sektor tanaman pangan sebesar 10,25 persen, sub sektor perkebunan rakyat sebesar 7,66 persen dan sub sektor peternakan sebesar 1,48 persen. Kenaikan NTP tertinggi selama tahun 2019 adalah sub sektor perikanan sebesar 8,52, persen dan sub sektor holtikultura sebesar 8,25 persen. Sedangkan untuk peramalan NTP pada aplikasi R menghasilkan:

$$
\begin{aligned}
& \operatorname{arima} 1=\operatorname{ARIMA}(1,1,0)=\text { aic }=163.99 \\
& \operatorname{arima2}=\operatorname{ARIMA}(0,1,0)=\text { aic }=164.73
\end{aligned}
$$

Model ARIMA terbaik yang sesuai adalah arima1 yakni ARIMA $(1,1,0)$ karena memiliki aic terkecil yakni 163.99, sigma ${ }^{2}$ estimated terkecil yakni 6.457 dan log likelihood terbesar dengan -79.99. Nilai ACF memenuhi white noise karena memiliki lag $\geq 1$ yang keluar batas dan residual tidak mengandung korelasi serial karena p-value for statistik Ljung boxnya diatas garis batas 5\%.

\section{Kesimpulan dan Saran}

Berdasarkan hasil penelitian yang penulis lakukan, diharapkan pemerintah Kabupa-ten Lamongan lebih memperhatikan sektor pertanian utamanya pada subsektor tanaman pangan, dimana tanaman pangan memiliki nilai NTP yang tergolong rendah yakni rata-rata $\geq 100$ pada setiap bulannya selama jangka waktu 3 tahun dan memiliki penurunan NTP tertinggi pada tahun 2019 sebesar 10,25\%. Misalnya dengan cara memperhatikan saluran irigasi agar dapat berfungsi dengan maksimal, mengontrol pembangunan pada beberapa tanah yang produktif, mengadakan sosialisasi tentang pem-

produksian hasil tanam. Serta pada sub sektor lain seperti sub sektor peternakan dan holtikultura yang memiliki penurunan pada 2 periode tahun yang cukup tinggi. 


\section{Daftar Pustaka}

Arifin, B. (2004). Analisis ekonomi pertanian Indonesia. Kompas.

Hendranata, A. (2003). ARIMA (Autoregressive Moving Average). Manajemen Keuangan Sektor Publik FEUI.

Prastowo, B. (2015). Potensi sektor pertanian sebagai penghasil dan pengguna energi terbarukan. Perspektif, 6(2), 85-93.

Rachmat, M. (2013). Nilai tukar petani: Konsep, pengukuran dan relevansinya sebagai indikator kesejahteraan petani. Forum Penelitian Agro Ekonomi, 31(2), 111-122.

RI, K. P. (2018). Pertumbuhan PDB Pertanian RI 2018 Melebihi Target. Retrieved January $30, \quad 2020, \quad$ from Jakarta website: https://www.pertanian.go.id/home/?show=news\&act=view\&id=3726

Rohmatullah, A., Rahmalia, D., \& Pradana, M. S. (2019). Klasterisasi Data Pertanian di Kabupaten Lamongan Menggunakan Algoritma K-Means Dan Fuzzy C Means. Jurnal Ilmiah Teknosains, 5(2), 86-93.

Statistik, B. P. (2018a). Booklet Survei Angkatan Kerja Nasional Februari 2018. Jakarta. Badan Pusat Statistik.

Statistik, B. P. (2018b). Produk Domestik Regional Bruto. Retrieved from Lamongan website: https://lamongankab.bps.go.id/statictable.html 